\title{
Incorporation of gold nanoparticles into Langmuir-Blodgett films of polyaniline and montmorillonite for enhanced detection of metallic ions
}

\author{
A. De Barros ${ }^{\mathrm{a}, \mathrm{b}}$, C.J.L. Constantino ${ }^{\mathrm{c}}$, J.R.R. Bortoleto ${ }^{\mathrm{d}}$, N.C. Da Cruz ${ }^{\mathrm{d}}$, M. Ferreira ${ }^{\mathrm{b}, *}$ \\ a Faculdade de Ciências, UNESP/POSMAT, Univ. Estadual Paulista, Bauru, SP, Brazil \\ ${ }^{\mathrm{b}}$ Universidade Federal de São Carlos, UFSCar, Campus Sorocaba, SP, Brazil \\ c Faculdade de Ciências e Tecnologia, UNESP Univ. Estadual Paulista, Presidente Prudente, SP, Brazil \\ d Campus Experimental de Sorocaba, UNESP Univ. Estadual Paulista, Sorocaba, SP, Brazil
}

\section{A R T I C L E I N F O}

\section{Article history:}

Received 9 March 2016

Received in revised form 25 May 2016

Accepted 2 June 2016

Available online 2 June 2016

\section{Keywords:}

Langmuir-Blodgett film

Gold nanoparticles

Polyaniline

Organophilic montmorillonite clay

Electrochemical sensors

Metallic ions detection

\begin{abstract}
A B S T R A C T
We report on effects from incorporating gold nanoparticles (AuNPs) into Langmuir-Blodgett (LB) films of emeraldine salt polyaniline (PAni-ES) and organophilic montmorillonite clay (OMt). The synergistic electrocatalytic effect induced by AuNPs led to an enhanced performance in detecting trace levels of cadmium $\left(\mathrm{Cd}^{2+}\right)$, lead $\left(\mathrm{Pb}^{2+}\right)$ and copper $\left(\mathrm{Cu}^{2+}\right)$ ions. Detection was carried out using square wave anodic stripping (SWAS) voltammetry using ITO electrodes modified with LB films made with three supramolecular architectures: PAni-ES/AuNPs, OMt/AuNPs and OMt/AuNPs/PAni-ES, and compared to LB films without AuNPs. The incorporation of AuNPs induced secondary doping of PAni-ES, inferred from FTIR, Raman and UV-vis. absorption spectroscopies. The PAni-ES chains probably became more extended and could intercalate into the OMt galleries, causing an increased interlayer spacing according to X-ray diffraction data. These results demonstrate the possible control of film properties by exploiting molecular-level interactions in multicomponent nanostructured films.
\end{abstract}

(c) 2016 Elsevier B.V. All rights reserved.

\section{Introduction}

The combination of two or more materials in a single device structure has become popular since synergy may be achieved in the materials properties, particularly when they are assembled in nanostructures [1-5]. In a number of applications, metallic nanoparticles are added to organic molecules to yield hybrids, with assembly via film-fabrication methods that allow for control of the molecular architecture, such as the Layer-by-Layer (LbL) and Langmuir-Blodgett (LB) techniques [6-10]. Gold nanoparticles (AuNPs), in particular, have had their catalytic activity and optical properties exploited in sensors, biosensors and electrochromic devices $[8,10-16]$. When stabilized or protected by a shell of thiolate ligands, AuNPs display good stability against aggregation, which enables exploration of their size-dependent properties, including quantum effects [12,17-19]. The influence of AuNPs on LB films of various materials has been reported in several instances. Tanami et al. [20] produced LB multilayers of PAni-ES and AuNPs

\footnotetext{
* Corresponding author.

E-mail address: marystela@ufscar.br (M. Ferreira).
}

where a composite was already formed at the air/water interface by electrostatic interaction between the negatively charged AuNPs dispersed in the water subphase and the positively charged PAni-ES molecules in the Langmuir film. The catalytic activity of these LB films depended on the AuNPs density, according to atomic force microscopy (AFM) and voltammetric analyses. Gupta et al. [7] controlled the assembly of hydrophobized AuNPs at the air/water interface by varying interfacial tension. Zou et al. [21] modified glass carbon electrodes with LB films of PAni-ES and AuNPs, which were used as voltammetric sensors for detecting epinephrene and uric acid. The incorporation of AuNPs increased the film catalytic activity. Medina-Plaza et al. [6,9] reported the synergistic electrocatalytic effect in sensors made of LB films with co-deposited AuNPs and phthalocyanine, where the coating with LB films led to a shift in reduction potential in the less positive direction, in comparison with the bare ITO electrode. The increased catalytic properties of the electrodes allowed for distinguishing between different dissociated protons of polyprotic acids. Furthermore, the presence of AuNPs led to an increased sensitivity toward organic acids and phenolic acids found in wines, reaching detection limits in the order of $\mu \mathrm{mol} \mathrm{L}{ }^{-1}$. García-Hernandéz et al. [22] investigated nanocomposite films of polypyrrole and AuNPs deposited on platinum and stainless 
steel $316 \mathrm{~L}$ disks. The films were obtained by in situ polymerization with AuNPs being incorporated either by electrooxidation and electrodeposition. Regardless of the fabrication method, the impedance data pointed to an increased conductivity and voltammetric signal in the presence of AuNps in the polymer matrix. While detecting catechol, the films deposited on platinum exhibited lower LODs compared to films deposited onto stainless steel 316 L disks, owing to synergy between AuNPs and platinum that facilitates electron transfer and improves electrocatalytic properties.

In this study, we aim at developing new materials (composite) where molecular control is key for enhanced sensing performance. In spite of the variety of contributions in the literature, monitoring of the environment still poses challenges that are worth pursuing. Sensing is sometimes made with films containing mercury or using mercury electrodes, which are not environmentally friendly and may be harmful to human health. Carbon paste electrodes have been used, with little or no impact to the environment, but the amount of material used is much larger than in nanostructured films. Therefore, exploring Langmuir-Blodgett (LB) films of tailored materials, such as the clays used here, may offer suitable sensitivity in addition to being environmentally friendly. Furthermore, clays promote cationic change with metal ions while interaction of gold nanoparticles and PAni-ES may increase electrical conductivity, thus enhancing electron transfer and electrocatalytic effects. In an earlier work we reported on synergistic effects between polyaniline emeraldine salt (PAni-ES) and organophilic montmorillonite clay mineral (OMt) in LB films [23], where molecular-level interactions were observed already in Langmuir films at the air/water interface. When deposited on indium tin oxide (ITO) substrates, these films served as sensing units to detect different metallic ions simultaneously, using electrochemical methods. Because this type of sensing may be further enhanced if metallic nanoparticles are incorporated $[9,16,21,24]$, in this work we studied the influence of AuNPs into Langmuir monolayers and then LB films of PAni-ES and OMt. Significant effects could be determined by resorting to different experimental techniques to characterize the films. Most importantly, the incorporation of AuNPs indeed improved the performance of sensing devices in detecting trace levels of cadmium $\left(\mathrm{Cd}^{2+}\right)$, lead $\left(\mathrm{Pb}^{2+}\right)$ and copper $\left(\mathrm{Cu}^{2+}\right)$ ions.

\section{Experimental}

\subsection{Instrumentation}

A Teflon ${ }^{\circledR}$ Langmuir trough model KSV 2000 was used for the fabrication of Langmuir and LB films. The quality of LB deposition was inferred from the transfer ratio (TR), defined as the ratio between the area of Langmuir film removed from the air-water interface, which is given by the displacement of the barriers to keep the surface pressure constant during LB layer deposition, and the substrate area coated by the deposited layer. The films were characterized by UV-vis absorption spectroscopy and microscopy analysis for LB films deposited onto quartz substrates. UV-vis absorption spectra were taken with a Genisys Thermo Scientific Spectrometer, model 6. FTIR and Raman spectra were obtained with LB films deposited onto silicon substrates, using a Thermo Nicolet spectrometer, model Nexus 470, and a micro-Raman Renishaw spectrograph, model in-Via, equipped with 1800 grooves/mm grating, CCD detector, $633 \mathrm{~nm}$ laser and a Leica microscope $(50 \times$ lens objective lens collecting spectra with ca. $1 \mu \mathrm{m}^{2}$ spatial resolution), with collection time of $10 \mathrm{~s}$ and spectral resolution of ca. $4 \mathrm{~cm}^{-1}$. X-ray diffraction (XRD) experiments were made with a PanAnalytical diffractometer ( $\mathrm{CuK} \alpha, \lambda=0.154 \mathrm{~nm})$ model ' $\mathrm{X}$ ' PertPro, for 20-layer LB films deposited onto silicon substrates. The spectra were taken with 0.05 step, exposure time of $3 \mathrm{~s}$, voltage of $45 \mathrm{kV}$ and current of $30 \mathrm{~mA}$. The basal distances were calculated from the peak position using the Bragg equation. Surface Plasmon Resonance (SPR) measurements were performed with a SPR BioNaves model SPR Navi ${ }^{\mathrm{TM}} 200$ and $670 \mathrm{~nm}$ laser, with films deposited onto Au plates. The surface topography of the samples was studied with atomic force microscopy (AFM, XE-100, Park Systems) operating in the non-contact mode and using silicon cantilevers whose nominal radius was $5.0 \mathrm{~nm}$. An area of $10.0 \mu \mathrm{m} \times 10.0 \mu \mathrm{m}$ was scanned at a resolution of $512 \times 512$ points. From the AFM images, the surface roughness was quantified using the root-mean-square (RMS) roughness. The voltammetry analysis was made with a saturated calomel reference electrode (SCE) and a platinum counter electrode with area of $1.0 \mathrm{~cm}^{2}$ with the LB films deposited on ITO substrate and covering an area of the working electrode of $1.5 \mathrm{~cm}^{2}$. A Potentiostat/Galvanostat, model PGSTAT 30, was coupled to the electrochemical cell, with measurements by square wave anodic stripping (SWAS) voltammetry. The analysis was made in an electrolyte containing three metal ions, $\mathrm{Cu}^{2+}, \mathrm{Pb}^{2+}$ and $\mathrm{Cd}^{2+}$, obtained from $\mathrm{PbCl}_{2}, \mathrm{CdCl}_{2} \cdot \mathrm{H}_{2} \mathrm{O}$ and $\mathrm{CuCl}_{2} \cdot 2 \mathrm{H}_{2} \mathrm{O}$ salts in several concentrations.

\subsection{Materials}

Tetrachloroauric acid $\left(\mathrm{HAuCl}_{4}\right)$, sodium 2-mercaptoethane sulfonate acid (MES) $\left(\mathrm{HSCH}_{2} \mathrm{CH}_{2} \mathrm{SO}_{3} \mathrm{Na}\right)$ and sodium borohydride $\left(\mathrm{NaBH}_{4}\right)$ were purchased from Sigma-Aldrich. The organophilic montmorillonite clay mineral (OMt) was acquired from Cloisite ${ }^{\circledR}$ Southern Clays.

\subsection{Procedures}

Gold nanoparticles (AuNPs) were obtained using the method described by Gofberg and Mandler [25], where the synthesis involves reduction of $\mathrm{HAuCl}_{4}$ by slowly adding $\mathrm{NaBH}_{4}$ in the presence of the MES ligand. The MES ligand is responsible for the improved stabilization of Au nanoparticles in the colloidal suspension, since it has two reactive groups: while the thiol group $(-\mathrm{SH})$ is able to form a strong covalent bond to Au nanoparticles, the sulfonic group $\left(\mathrm{SO}_{3}{ }^{-}\right)$facilitates interaction with other molecules. In the synthesis, $0.0394 \mathrm{~g}$ of $\mathrm{HAuCl}_{4}$ and $0.0164 \mathrm{~g}$ were dissolved in $36.0 \mathrm{~mL}$ of water/acetic acid (final $\mathrm{pH} 3$ ) and stirred for $10 \mathrm{~min}$ at room temperature. The reduction of nanoparticles was obtained by addition of $7.6 \mathrm{mg} \mathrm{NaBH} 4$ dissolved in $10.0 \mathrm{~mL}$ of deionized water, with the solution slowly becoming deep purple and stirred for $2 \mathrm{~h}$. The AuNPs were precipitated by addition of acetonitrile (ACN); after precipitation and decantation of ACN the sample was rinsed twice with $5.0 \mathrm{~mL}$ of ethanol and decanted. Then, the sample was suspended in an aqueous solution, $\mathrm{pH}$ 2.5. The colloid of gold nanoparticles was characterized by UV-vis absorption spectroscopy, with total reduction of gold salt showing the plasmonic band at $525 \mathrm{~nm}$. The shape and size of these nanoparticles were consistent with the literature [25] characterized by transmission electronic microscopy (TEM), with an average diameter of $3.2 \mathrm{~nm}$. It is noteworthy that these nanoparticles have a negative surface charge due to the sulfonic group $\left(\mathrm{SO}_{3}{ }^{-} \mathrm{Na}^{+}\right)$at the end of the thiol structure [26]. Further details of this characterization are discussed in Supplementary information.

OMt was prepared following procedures established by Kotov et al. [27] The dispersion of OMt was obtained by sonication in a butanol-benzene mixture $(1: 1, \mathrm{v} / \mathrm{v})$. The PAni-ES solution was prepared as described by Riul et al. [28], with $1.0 \mathrm{mg}$ of polyaniline emeraldine base (PAni-EB) being doped with $1.3 \mathrm{mg}$ of camphorsulfonic acid (CSA) and dissolved in $1.0 \mathrm{~mL}$ of $\mathrm{m}$-cresol and $9.0 \mathrm{~mL}$ of chloroform.

The Langmuir films were produced by co-spreading PAni-ES solution and/or OMt dispersion with different concentrations of 

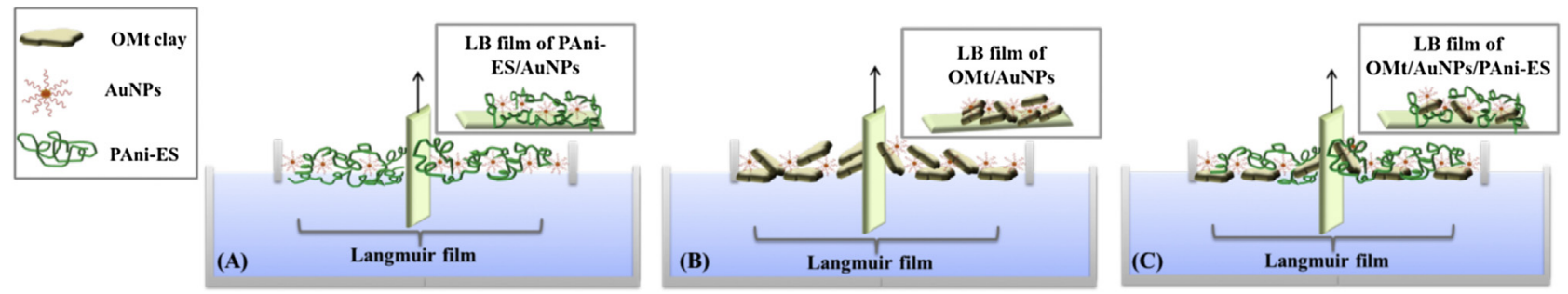

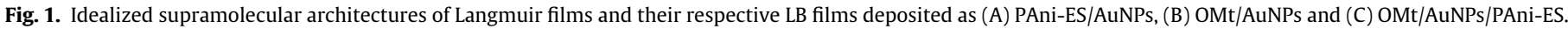

AuNPs on aqueous subphases containing purified water by a Millipore ${ }^{\circledR}$ system (resistivity $18.2 \mathrm{M} \Omega \mathrm{cm}$ ) with $\mathrm{pH}$ adjusted to 2.5 with $\mathrm{HCl}$. After spreading $50 \mu \mathrm{L}$ of OMt $\left(\mathrm{MW}=2892.48 \mathrm{~g} \mathrm{~mol}^{-1}\right)$ dispersion, $40 \mathrm{~min}$ were allowed for solvent evaporation. For the PAni-ES (MW $=362.0 \mathrm{~g} \mathrm{~mol}^{-1}$ ) solution, $750 \mu \mathrm{L}$ were spread onto the water surface, with 15 min being allowed for solvent evaporation. The surface pressure was measured with a Wilhelmy plate and film compression was symmetrically performed with two movable barriers at a rate of $10.0 \mathrm{~mm} \mathrm{~min}^{-1}$. The Langmuir films were transferred onto quartz, silicon and ITO to produce Z-type LB films with three types of supramolecular architectures: (i) PAniES/AuNPs, (ii) OMt/AuNPs and (iii) OMt/AuNPs/PAni-ES. The LB deposition was performed at $30.0 \mathrm{mN} \mathrm{m}^{-1}$ for PAni-ES/AuNPs and OMt/AuNPs/PAni-ES, and at $40.0 \mathrm{mN} \mathrm{m}^{-1}$ for OMt/AuNPs, which was sufficiently high to ensure a condensed state, but avoiding collapse. An interval of 30 min was used in between two dipping procedures, with a dipping rate of $1.5 \mathrm{~mm} \mathrm{~min}^{-1}$ for all cases. The Z-type LB film means that the deposition occurs only when the substrate is removed from the aqueous subphase (upstroke). The transfer ratio (TR) for these three LB films was in average 0.85 for PAni-ES/AuNPs, 0.95 for OMt/AuNPs and 0.90 for the nanocomposite OMt/AuNPs/PAni-ES. Fig. 1 shows the idealized supramolecular architectures for the Langmuir films and their respective LB films.

\section{Results and discussion}

The incorporation of increasing amounts of AuNPs in the subphase caused a shift in the $\pi$-A isotherms of PAni-ES/OMt, in addition to increasing the collapse pressure, as shown in Fig. 2(A). The increase in extrapolated area for the condensed phase is clear in Fig. 2(B), while Fig. 2(C) shows a non-additive behavior for adding PAni-ES to OMt, owing to molecular-level interactions discussed in detail by de Barros et al. [23]

Apart from the shift in area per repeating unit with the addition of AuNPs, as expected since the Langmuir films incorporate the nanoparticles, one cannot infer which type of interaction was involved. We have attempted to determine such interactions by characterizing the deposited LB films, with the transfer of Langmuir films of PAni-ES/AuNPs, OMt/AuNPs and OMt/AuNPs/PAni-ES onto solid substrates. Fig. 3(A) shows the UV-vis absorption spectra of Z-type LB films of PAni-ES film and AuNPs, featuring three bands assigned to PAni-ES at 300,400 and $830 \mathrm{~nm}$, which correspond respectively to the $\pi-\pi^{*}$ transition, the anti-ligand $\left(\pi^{*}\right)$ transition in the polaronic band and the polaronic state due to CSA doping [29]. Compared to the polaronic band without AuNPs at $750 \mathrm{~nm}$ [23], the band shift to $830 \mathrm{~nm}$ suggests secondary doping, which may occur due to interaction of sulfonic groups $\left(\mathrm{SO}_{3}{ }^{-}\right)$from the thiol ligands encapsulating the gold nanoparticles [26]. Absorption increased linearly with the number of layers in the LB films, i.e. the same amount of material was deposited in each transfer step. The spectra for the OMt/AuNPs LB film in Fig. 3(B) display a band at $250 \mathrm{~nm}$ assigned to a charge transfer transition on $\mathrm{Fe}-\mathrm{OH}$ groups from OMt [30]. The interactions between AuNPs and OMt favor adsorption with linear growth with the number of bilayers and
Table 1

Thickness obtained from SPR data and roughness by AFM analysis for 5-layer LB films with and without AuNPs.

\begin{tabular}{lll}
\hline LB films & Thickness $(\mathrm{nm})$ & RMS $(\mathrm{nm})$ \\
\hline PAni-ES & $4.7 \pm 0.1$ & 2.8 \\
PAni-ES/AuNPs & $3.9 \pm 0.3$ & 2.7 \\
OMt & $3.3 \pm 0.3$ & 9.2 \\
OMt/AuNPs & $0.67 \pm 0.01$ & 4.5 \\
OMt/PAni-ES & $2.2 \pm 0.2$ & 1.6 \\
OMt/AuNPs/PAni-ES & $3.0 \pm 0.1$ & 2.3 \\
\hline
\end{tabular}

better reproducibility than neat OMt clay LB films observed from the UV-vis characterization. The spectra for OMt/AuNPs/PAni-ES LB film in Fig. 3(C) are dominated by bands of PAni-ES, with the OMt band being masked by the PAni-ES band at $300 \mathrm{~nm}$. Note that the polaronic bands are shifted to $800 \mathrm{~nm}$ in comparison to the LB films of OMt/PAni-ES without AuNPs (740 nm [23]). The exponential growth for this LB film may be associated with preferential adsorption of PAni-ES and AuNPs based on the stronger interactions between these materials (see further discussion about this issue when the FTIR and Raman data are analyzed). Because of encapsulation by the thiol, the plasmonic band of AuNPs at $525 \mathrm{~nm}$ is not apparent in either LB films.

Film growth onto gold plates was also monitored with SPR, whose data are given in Fig. 4. A shift in the SPR signal toward increasing angle is observed for the PAni-ES/AuNPs LB film in Fig. 4(A), indicating an improved ordering induced by AuNPs. The influence of AuNPs can be compared with the neat OMt LB film in de Barros et al. [23], resulting in the ordering improved for the OMt/AuNPs LB film in Fig. 4(B). Film thickness increased linearly with the number of deposited layers, consistent with the UV-vis absorption data. For the mixed LB films of OMt/AuNPs/PAni-ES in Fig. $4(\mathrm{C})$, there was also stronger ordering induced by the AuNPs. Film thickness increased exponentially with the number of layers.

Incorporation of AuNPs caused the LB film thickness to decrease for PAni-ES and OMt, as indicated in Table 1. Since the AuNPs are capped with a charged group $\left(\mathrm{SO}_{3}{ }^{-}\right)$, one could expected such charges to interact with the PAni-ES chain, thus leading to coiled polymer structures that should increase film thickness. However, the UV-vis spectra (and the FTIR and Raman spectra to be presented later on) did indicate that AuNPs induced further secondary doping in PAni-ES, which may have caused the chains to be more extended. As for the OMt/AuNPs/PAni-ES LB films, on the other hand, the insertion of AuNPs led to an increased thickness, as the more extended PAni-ES chains could be intercalated into the OMt galleries (see the XRD analysis below), which was not observed for the OMt/PAni-ES [23]. Also shown in Table 1 are the film roughness values obtained from AFM images; roughness increases with film thickness. Fig. 5 shows AFM images of 1-layer LB films, where incorporation of AuNPs made PAni-ES films more homogeneous, but the roughness of OMt/AuNP/PAni-ES was higher than for OMt/PAni-ES owing to OMt exfoliation.

In order to understand why AuNPs have such strong effects on the properties of PAni-ES and their influence on the structuring 


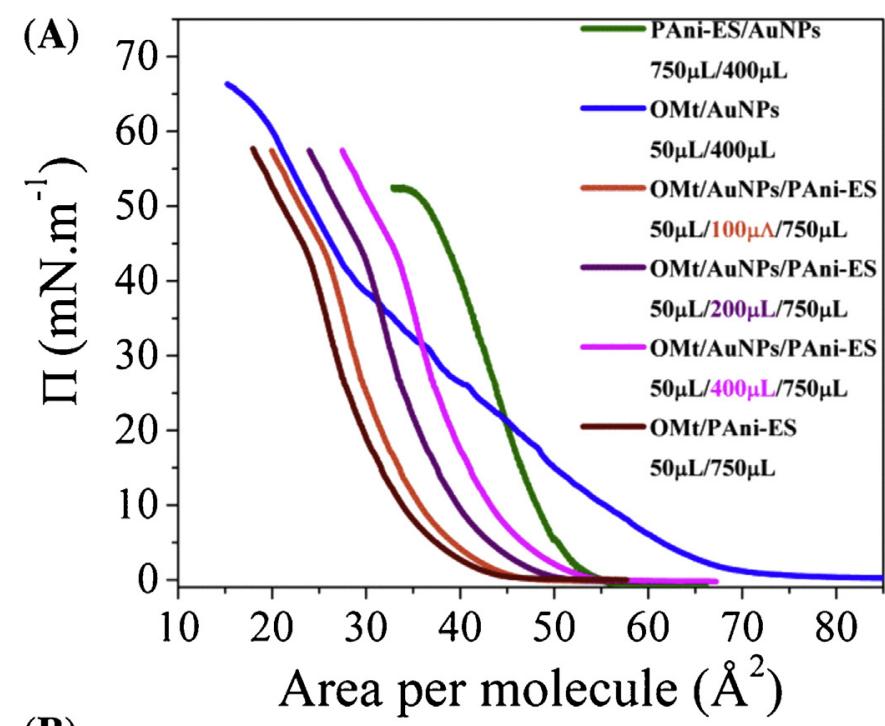

(B)

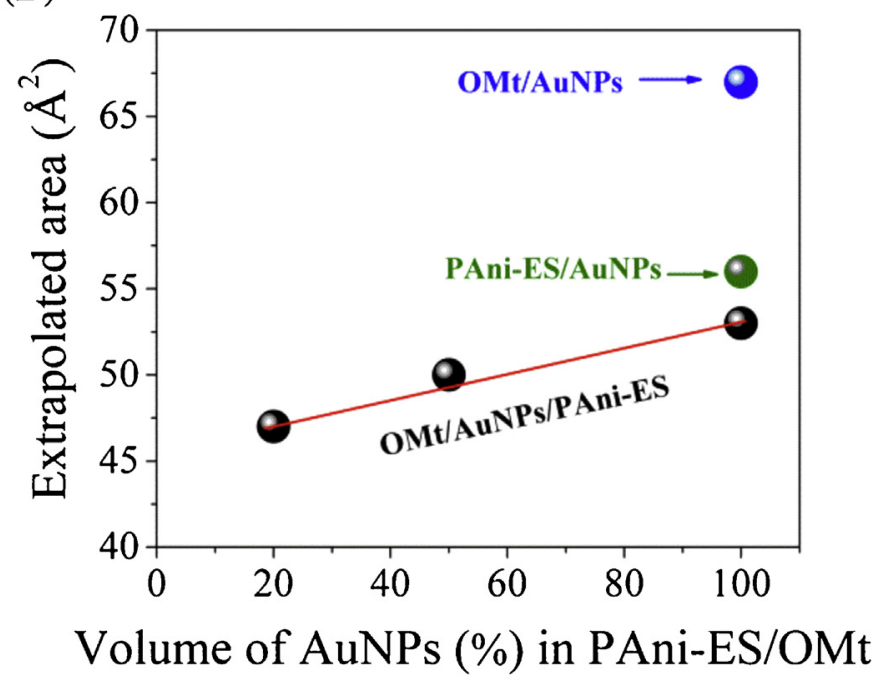

(C)

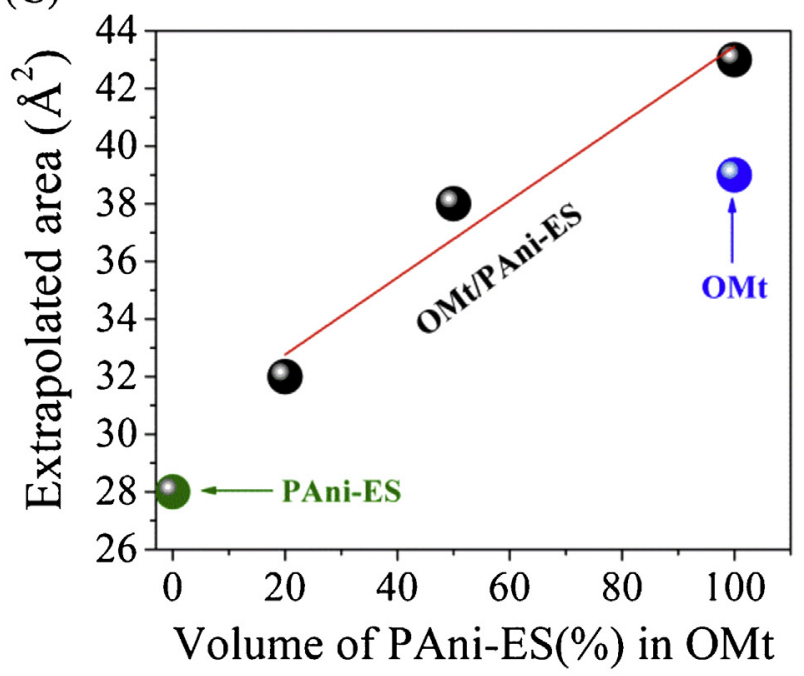

Fig. 2. (A) comparison of $\pi$-A isotherms for Langmuir films for PAni-ES/AuNPs, OMt/AuNPs and nanocomposites with distinct OMt/AuNPs/PAni-ES relative concentrations. (B) Extrapolated area for the various Langmuir films versus volume (\%) samples of AuNPs mixture with OMt and PAni-ES. (C) Extrapolated area for the various Langmuir films versus volume samples of OMt mixture with PAni-ES without AuNPs, figure adapted from Ref. [23] for comparison. The extrapolated area was obtained by prolonging the isotherm at small areas (condensed film) down to zero pressure, with the value of the area being taken as the intercept with the abscissa.

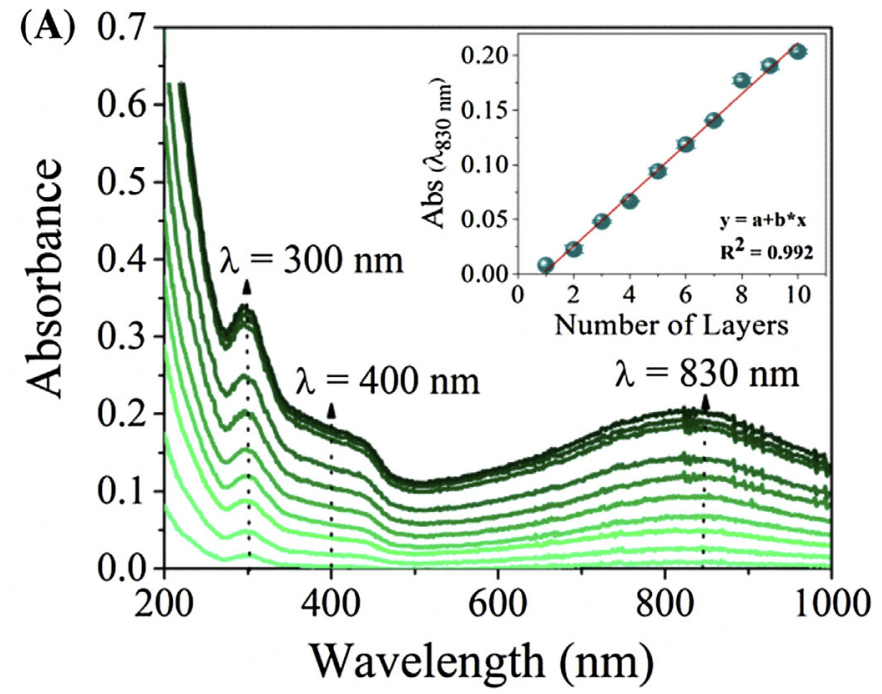

(B)

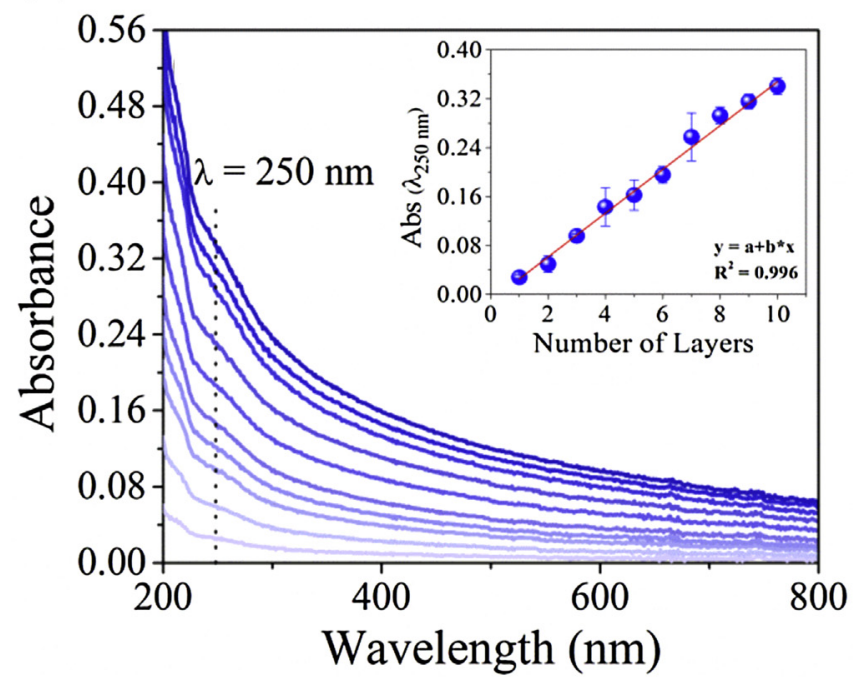

(C)

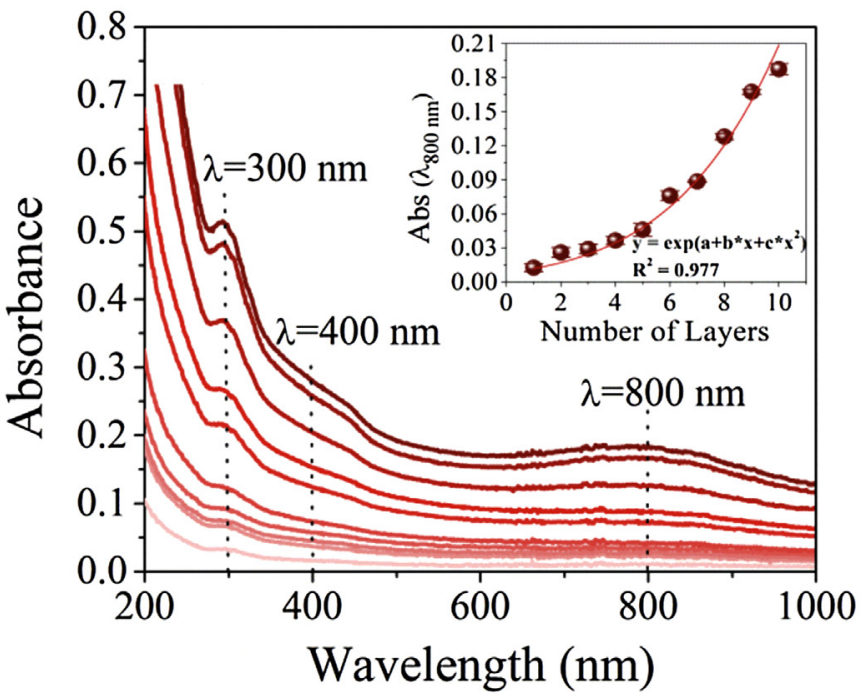

Fig. 3. UV-vis spectra for LB films deposited onto quartz plates up to 10 layers of PAni-ES/AuNPs (A), OMt/AuNPs (B) and OMt/AuNPs/PAni-ES (C). The insets depict film growth with plots of absorbance versus number of layers deposited. Absorbance was recorded at $830 \mathrm{~nm}$ for (A) PAni-ES/AuNPs, at $250 \mathrm{~nm}$ for (B) OMt/AuNPs, and at $800 \mathrm{~nm}$ for (C) OMt/AuNPs/PAni-ES. 


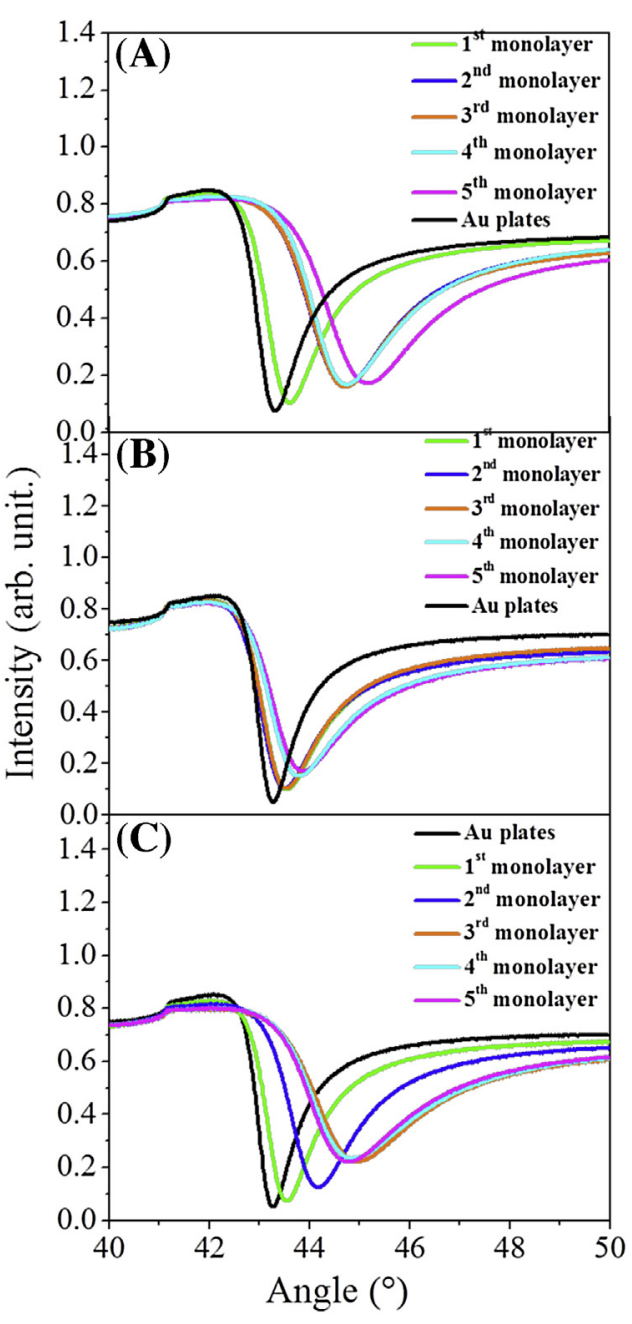

Fig. 4. SPR curves with the impinging laser at $670 \mathrm{~nm}$ for LB films: (A) PAniES/AuNPs, (B) OMt/AuNPs and (C) OMt/AuNPs/PAni-ES, deposited onto Au plates.

Table 2

Comparison of basal spacing values calculated for the LB films with and without AuNPs.

\begin{tabular}{lll}
\hline & $2 \theta$ (degree) & Lamellar Spaces $(\mathrm{nm})$ \\
\hline${ }^{\mathrm{a}}$ LB film OMt & 4.93 & 1.79 \\
LB film OMt/AuNPs & 5.00 & 1.76 \\
a LB film OMt/PAni-ES & 4.93 & 1.79 \\
LB film OMt/AuNPs/PAni-ES & 4.87 & 1.81 \\
\hline
\end{tabular}

a Values extracted from de Barros et al. [23].

of stacks to the LB film containing OMt clay, we characterized the films with three other methods, namely X-ray diffraction (XRD), FTIR and Raman spectroscopy. The XRD patterns in Fig. 6 for OMt/AuNPs and OMt/AuNPs/PAni-ES LB films illustrate the effects of adding AuNPs. The peak at $4.93^{\circ}$ for the neat OMt LB film [23] was shifted to $5.00^{\circ}$ and $4.87^{\circ}$ for OMt/AuNPs and OMt/AuNPs/PAni$\mathrm{ES}$, respectively. The interlayer spacing calculated using the Bragg equation is $1.76 \mathrm{~nm}$ for OMt/AuNPs LB film and $1.81 \mathrm{~nm}$ for the OMt/AuNPs/PAni-ES mixed LB film, to be compared with $1.79 \mathrm{~nm}$ for the neat LB film of OMt (see Table 2). The increased interlayer spacing is indicative of intercalation of PAni-ES extended chains in the OMt galleries [31-33]. The decrease in interlayer spacing for OMt in OMt/AuNPs LB film, on the other hand, is possibly caused by changes in OMt stacking responsible for the large decrease in layer thickness (see Table 1 ).
The band shift in the UV-vis spectra for the polaronic band of PAni-ES in Fig. 3 pointed to molecular-level interactions of PAni-ES and AuNPs, which was confirmed with FTIR and Raman spectroscopies. Fig. 7 shows the FTIR spectra in the transmittance mode for 25-layer LB films of PAni-ES/AuNPs, OMt/AuNPs/PAni-ES and OMt/AuNPs, also including the spectra of LB films of neat PAniES and OMt for comparison. The main changes in the spectrum of PAni-ES/AuNPs are the shift of the peaks at 1170 and $1316 \mathrm{~cm}^{-1}$ assigned to $\mathrm{N}=\mathrm{Q}=\mathrm{N}$ and $\mathrm{N}-\mathrm{B}-\mathrm{N}$ modes, and at $1248 \mathrm{~cm}^{-1}$ assigned to an in-plane bending vibration of $\mathrm{Q}=\mathrm{N}^{+} \mathrm{H}-\mathrm{B}$ and $\mathrm{B}-\mathrm{N}^{+} \mathrm{H}-\mathrm{B}$ ( $\mathrm{Q}$ corresponding to quinoid rings and $B$ to benzenoid rings). [32-36] The interaction between PAni-ES and AuNPs is revealed by the appearance of the peak at $1118 \mathrm{~cm}^{-1}$, assigned to interaction between sulfonic groups $\left(\mathrm{SO}_{3}{ }^{-}\right)$of the thiol ligand and PAni-ES, promoting secondary doping in PAni-ES [17]. The latter was confirmed in the Raman spectra with the shift of the polaronic band, as discussed later on. The strong molecular interaction between PAni-ES and AuNPs is also observed for all peaks attributed to PAni-ES in the LB mixed film OMt/AuNPs/PAni-ES, which was not observed for the OMt/PAni-ES LB film. Table 3 highlights the differences for the peaks of PAni-ES and PAni-ES/OMt in the presence of AuNPs in LB films.

Also consistent with the FTIR results, the Raman spectra in Fig. 8 show differences between the spectra for PAni-ES/AuNPs and OMt/AuNPs/PAni-ES LB films compared to the LB films without AuNPs. The peak assignments are given in Table 4. The discernible differences are again in the polaronic state of PAni-ES for the LB film of PAni-ES/AuNPs and OMt/AuNPs/PAni-ES. For instance, the peak at $1335 \mathrm{~cm}^{-1}$ for PAni-ES and OMt/PAni-ES LB film is shifted to 1339 and $1340 \mathrm{~cm}^{-1}$ for PAni-ES/AuNPs and OMt/AuNPs/PAni$\mathrm{ES}$, respectively. There was also significant change in the bands at 1639 and $1640 \mathrm{~cm}^{-1}$ for PAni-ES/AuNPs and OMt/AuNPs/PAni-ES, which appear at 1632 and $1650 \mathrm{~cm}^{-1}$ for PAni-ES and OMt/PAni-ES LB film. The OMt/AuNPs LB film does not show characteristic Raman bands; there is only a decrease in the scattering background due to the incorporation of AuNPs in OMt films.

The electrochemical activity of the LB films can be exploited to detect metal ions using SWAS voltammetry. Figs. 9(A)-(C) show SWAS voltammograms for PAni-ES/AuNPs, OMt/AuNPs and OMt/AuNPs/PAni-ES LB films deposited onto ITO electrodes, respectively. All the electrodes were able to distinguish between the three metal ions, as indicated by the oxidation peaks. A more clear distinction was achieved for separation peaks without the overlap with the PAni-ES peaks, due to the presence of AuNPs in the LB films, which also cause considerable increase in the current intensity in the voltammograms. The peak current increased with the metal concentration, which allowed us to determine the sensitivity and limit of detection (LOD) from the analytical curves in Fig. 10(A)-(C). These values are given in Table 5, where a comparison is made with LB films of PAni-ES, OMt and PAni-ES/OMt without AuNPs, and with LOD values in the literature obtained with differential pulse voltammetry (DPV). The LOD values obtained via cyclic voltammetry with the LB films in this work are compared for the different metal ions.

In a direct comparison of the performance of the three modified electrodes, one could infer that the OMt/AuNPs/PAni-ES LB film was superior, judging by the data in Table 5 . In all cases the peaks for different electrodes in Fig. $9(\mathrm{~A})-(\mathrm{C})$ appear at $\mathrm{E}=-0.6 \mathrm{~V}, \mathrm{E}=-0.45 \mathrm{~V}$ and $\mathrm{E}=-0.26 \mathrm{~V}$ for $\mathrm{Cd}^{2+}, \mathrm{Pb}^{2+}$ and $\mathrm{Cu}^{2+}$ ions, respectively, which are shifted considerably from the expected potentials from the literature and when compared to the LB films of PAni-ES and OMt without AuNPs, which should be $\mathrm{E}^{\circ}=-0.75 \mathrm{~V}$ for $\mathrm{Cd}^{2+}, \mathrm{E}^{\circ}=-0.51 \mathrm{~V}$ for $\mathrm{Pb}^{2+}$ and $\mathrm{E}^{\circ}=+0.34 \mathrm{~V}$ for $\mathrm{Cu}^{2+}[23,42-45]$. We conclude that the electrode coated with OMt/AuNPs/PAni-ES is the most efficient in detecting the three metal ions simultaneously because separation is more efficient and the limit of detection (LOD) (determined from 
Table 3

Comparison and assignment of the FTIR bands for the LB films with and without AuNPs.

\begin{tabular}{|c|c|c|c|c|}
\hline \multirow{2}{*}{$\begin{array}{l}\text { Assignment } \\
\text { PAni-ES }\end{array}$} & \multicolumn{4}{|c|}{ Wavenumber $\left(\mathrm{cm}^{-1}\right)$} \\
\hline & ${ }^{a}$ LB filmPAni-ES & LB filmPAni-ES/AuNPs & ${ }^{\mathrm{a}} \mathrm{LB}$ filmOMt/PAni-ES & LB filmOMt/AuNPs/PAni-ES \\
\hline Secondary doping $\mathrm{C}-\mathrm{N}-\mathrm{SO}_{3}{ }^{-}$ & - & 1118 & - & 1118 \\
\hline Vibrational mode, $\mathrm{N}=\mathrm{Q}=\mathrm{N}$ in the plane & 1162 & 1170 & - & 1170 \\
\hline $\mathrm{QN}^{+} \mathrm{H}-\mathrm{B}$ or $\mathrm{B}-\mathrm{N}^{+} \mathrm{H}-\mathrm{B}$ stretching radical cation & 1250 & 1298 & - & 1248 \\
\hline Vibrational mode, $\mathrm{N}=\mathrm{B}=\mathrm{N}$ in the plane & 1310 & 1316 & - & 1316 \\
\hline $\mathrm{C}=\mathrm{C}$ stretching (benzenoid ring) & 1496 & 1500 & 1496 & 1500 \\
\hline $\mathrm{C}=\mathrm{C}$ stretching (quinoid ring) & 1586 & 1592 & 1586 & 1592 \\
\hline
\end{tabular}

a Values extracted from de Barros et al. [23].

Table 4

Assignment of Raman bands for the LB films within and without of AuNPs.

\begin{tabular}{|c|c|c|c|c|}
\hline \multirow{2}{*}{$\begin{array}{l}\text { Assignment } \\
\text { PAni-ES }\end{array}$} & \multicolumn{4}{|c|}{ Wavenumber $\left(\mathrm{cm}^{-1}\right)$} \\
\hline & ${ }^{\mathrm{a}} \mathrm{LB}$ filmPAni-ES & LB filmPAni-ES/AuNPs & ${ }^{\mathrm{a}} \mathrm{LB}$ filmOMt/PAni-ES & LB filmOMt/AuNPs/PAni-ES \\
\hline Cation radical stretching $\mathrm{C}-\mathrm{N}^{+}$ & 1335 & 1340 & 1335 & 1340 \\
\hline Stretching of benzene ring & 1640 & 1650 & 1650 & 1650 \\
\hline
\end{tabular}

a Values extracted from de Barroset al. [23].
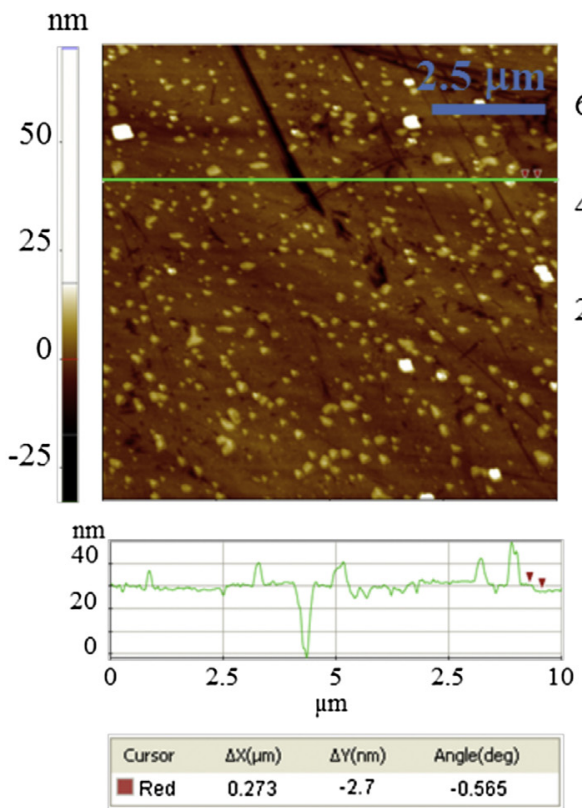

$\mathrm{nm}$
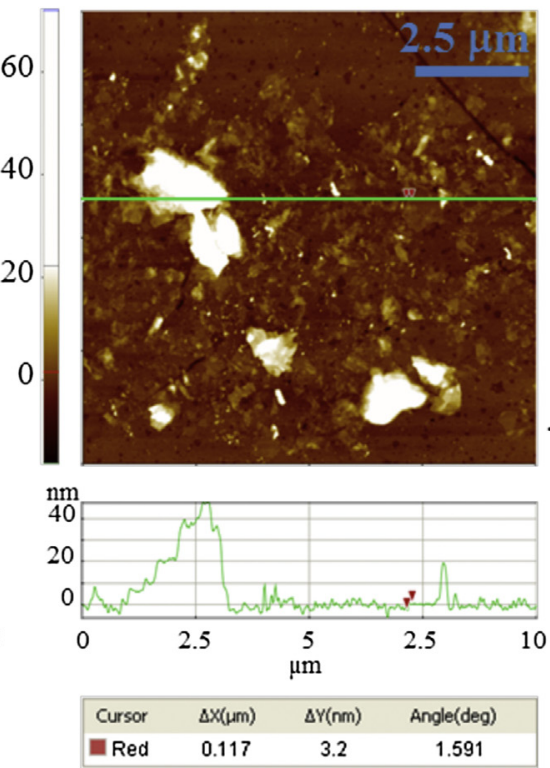
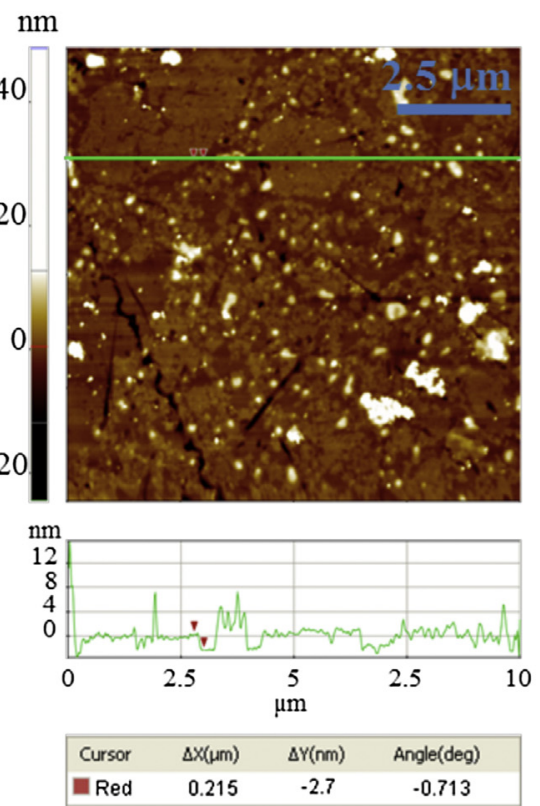

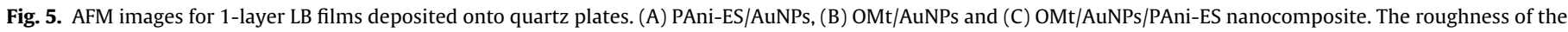
quartz plates was calculated as $0.8 \mathrm{~nm}$.

Table 5

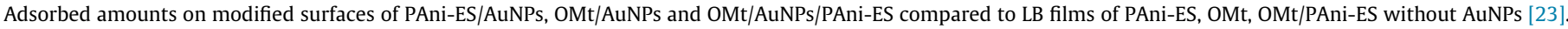
For the sake of comparison, also included were the LOD values for metal ion detection from different methods (CV and DPV).

\begin{tabular}{|c|c|c|c|c|c|c|c|c|}
\hline \multirow[t]{2}{*}{$\begin{array}{l}\text { Analyte (metallic } \\
\text { ions) }\end{array}$} & \multirow[t]{2}{*}{$\begin{array}{l}\text { Electrode } \\
\text { Modified }\end{array}$} & \multirow{2}{*}{$\begin{array}{l}\text { Sensitivity for } \\
\text { individual metal } \\
\text { ions } \\
\left(\mu \mathrm{Acm}^{-2} \mathrm{mg} \mathrm{L}^{-1}\right)\end{array}$} & \multirow[t]{2}{*}{$\begin{array}{l}\text { Sensitivity } \\
\left(\mu \mathrm{Acm}^{-2} \mathrm{mg} \mathrm{L}^{-1}\right)\end{array}$} & \multirow[t]{2}{*}{$\operatorname{LOD}\left(\mathrm{mg} \mathrm{L}^{-1}\right)$} & \multirow[t]{2}{*}{$\begin{array}{l}\text { Electrode } \\
\text { Modified } \\
\text { (without AuNPs) }\end{array}$} & \multirow[t]{2}{*}{$\operatorname{LOD}\left(\mathrm{mg} \mathrm{L}^{-1}\right)$} & \multicolumn{2}{|c|}{$\begin{array}{l}\text { Comparison of LOD } \\
\text { with other } \\
\text { methods }\left(\mathrm{mg} \mathrm{L}^{-1}\right)\end{array}$} \\
\hline & & & & & & & $\begin{array}{l}\text { Cyclic } \\
\text { voltammetry } \\
(\mathrm{VC})\end{array}$ & $\begin{array}{l}\text { Differential pulse } \\
\text { voltammetry } \\
(\mathrm{DPV})\end{array}$ \\
\hline $\mathrm{Cd}^{2+}$ & PAni-ES/AuNPs & $270 \pm 2$ & $272 \pm 2$ & 0.02 & PAni-ES & 0.2 & 0.4 & $0.3[37]$ \\
\hline $\mathrm{Pb}^{2+}$ & & $33.1 \pm 0.1$ & $34.1 \pm 0.2$ & 0.02 & & 0.2 & 0.2 & $0.03[37]$ \\
\hline $\mathrm{Cu}^{2+}$ & & $3.8 \pm 0.07$ & $3.74 \pm 0.07$ & 0.05 & & 0.04 & 101 & $0.4[38]$ \\
\hline $\mathrm{Cd}^{2+}$ & OMt/AuNPs & $272 \pm 2$ & $279 \pm 2$ & 0.02 & OMt & 0.2 & 0.5 & $0.1[39]$ \\
\hline $\mathrm{Pb}^{2+}$ & & $55.8 \pm 0.7$ & $56.2 \pm 0.7$ & 0.04 & & 0.4 & 0.3 & $0.4[39]$ \\
\hline $\mathrm{Cu}^{2+}$ & & $7.8 \pm 0.2$ & $8.1 \pm 0.2$ & 0.07 & & 0.2 & 77 & $0.2[39]$ \\
\hline $\mathrm{Cd}^{2+}$ & OMt/AuNPs/PAni-ES & $307.1 \pm 0.5$ & $307.5 \pm 0.5$ & 0.005 & OMt/ PAni-ES & 0.2 & 0.2 & $0.09[40]$ \\
\hline $\mathrm{Pb}^{2+}$ & & $767 \pm 1$ & $767.4 \pm 1.6$ & 0.006 & & 0.2 & 0.1 & $0.02[40]$ \\
\hline $\mathrm{Cu}^{2+}$ & & $34.1 \pm 0.1$ & $33.9 \pm 0.1$ & 0.009 & & 0.2 & 34 & $0.9[41]$ \\
\hline
\end{tabular}




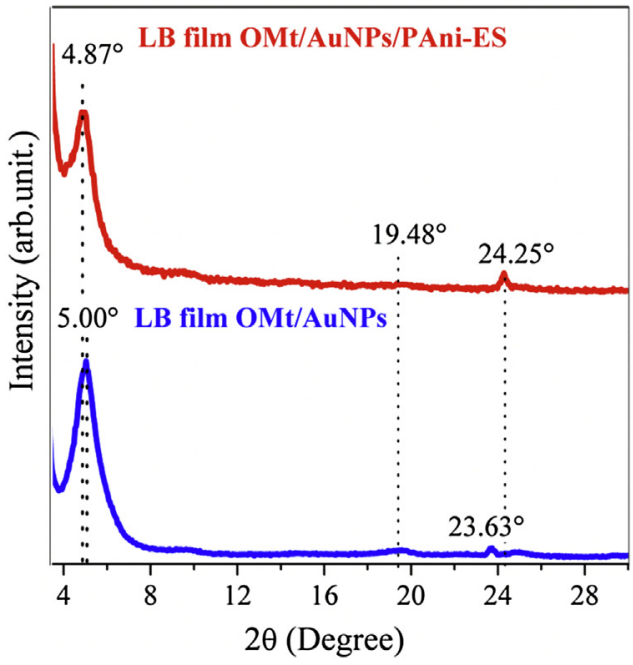

Fig. 6. XRD patterns for 25-layer LB films of OMt/AuNPs/PAni-ES and OMt/AuNPs deposited onto silicon plates.

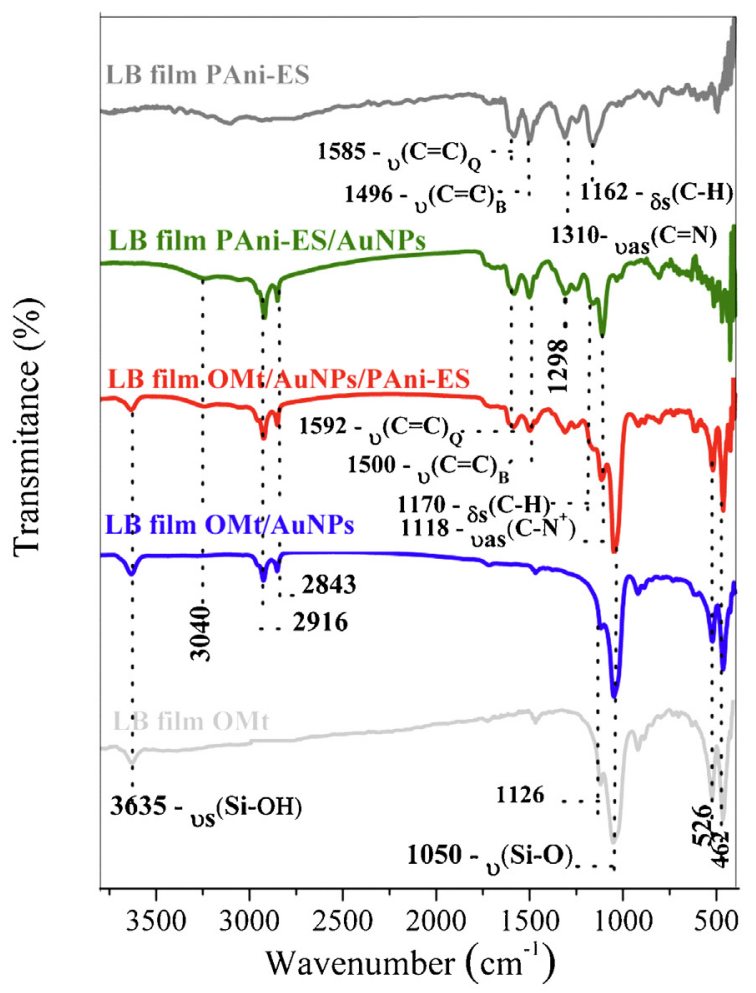

Fig. 7. FTIR spectra recorded in transmition mode for 25-layer LB films composed of PAni/AuNPs, OMt/AuNPs/PAni-ES and OMt/AuNPs, deposited onto silicon substrate. The spectra in dark and light gray lines correspond to 50-layer LB films of neat PAni-ES and OMt, respectively.

the analytical curves in Fig. 10) is lower than for the LB films made of PAni-ES and OMt without AuNPs. A direct comparison was possible owing to the similar response with these materials without AuNPs immobilized by the LB technique [23]. In summary, this superior performance for the OMt/AuNPs/PAni-ES LB film points to synergy between the materials in this sensing task and high electrocatalytic activity promoted by AuNPs.

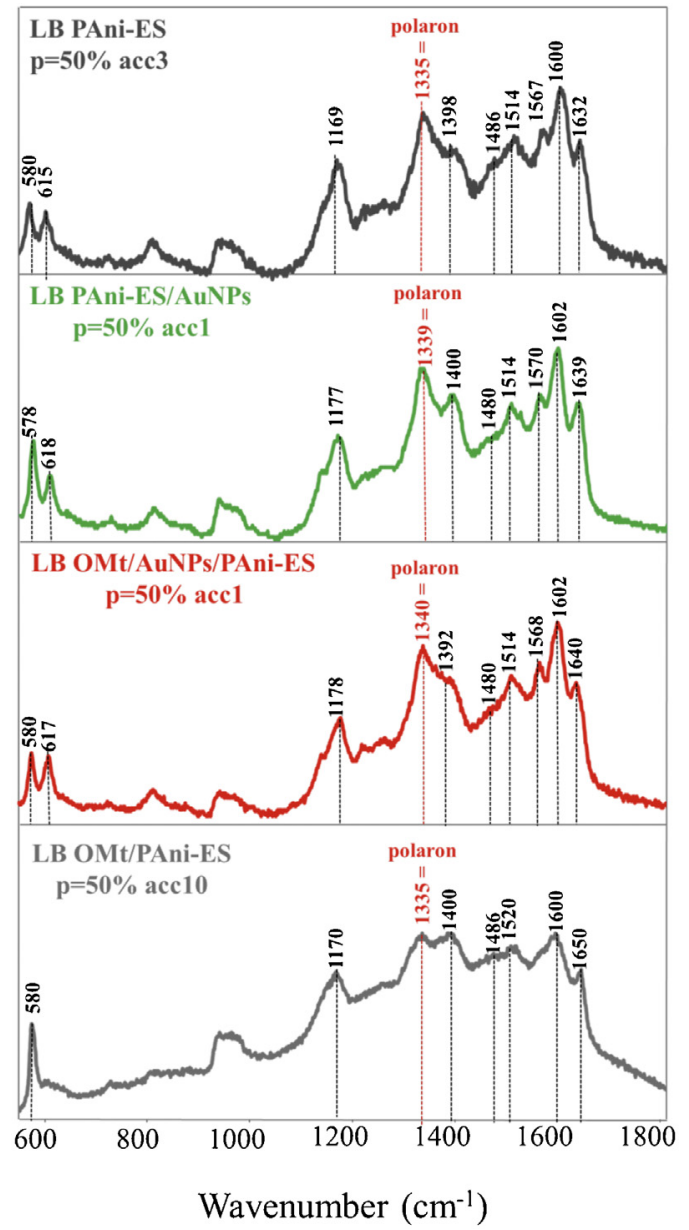

Fig. 8. Raman spectra for 25-layer LB films onto silicon substrates for PAni-ES/AuNPs and OMt/AuNPs/PAni-ES. The spectra in dark and light gray lines correspond to neat LB films of PAni-ES and OMt clay mineral, respectively.

\section{Conclusion}

The presence of AuNPs in the LB films of PAni-ES and OMt clay promoted stabilization of mixed Langmuir films (PAni-ES/AuNPs, OMt/AuNPs and PAni-ES/OMt/AuNPs) at the air-water interface. This higher stability was possibly responsible for the more homogenous mixed LB films when compared to neat LB films (PAni-ES and OMt), as indicated in the AFM and SPR analyses. We suggest that an interaction between PAni-ES and AuNPs causes unfolding of the polymer chain favoring intercalation in the lamellar clay spaces, which is supported by X-ray diffraction data with an increased basal spacing of clay layers. FTIR and Raman spectra confirmed the effect of AuNPs on PAni-ES with a significant shift in its polaronic state, ascribed to secondary doping. Furthermore, incorporation of AuNPs in LB films made with PAni-ES and OMt enhanced the electrocatalytic effect for detecting metal ions, yielding a higher performance with lower limit of detection.

\section{Acknowledgements}

This work was supported by FAPESP (Grants 2011/00733-2 and 2012/16158-0), CNPq (Grant 473222/2012-4), CAPES, and nBioNet network. The authors are also grategul to Prof. Osvaldo N. Oliveira Jr for helpful discussions, to Sabrina Aléssio Camacho for the help with the Raman measurements and Rafael Parra Ribeiro for the help with XRD analysis. 

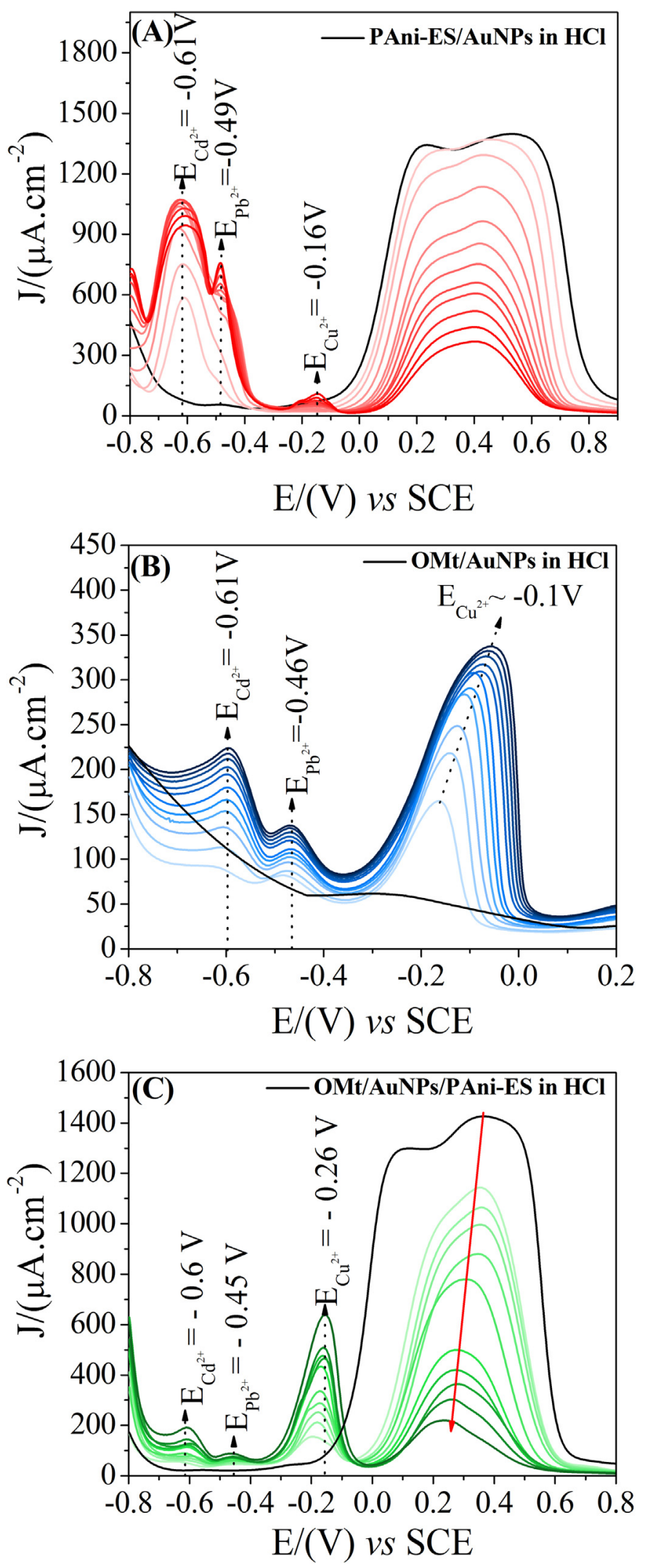

Fig. 9. Square wave anodic stripping voltammograms for simultaneous detection of $\mathrm{Cu}^{2+}, \mathrm{Pb}^{2+}$ and $\mathrm{Cd}^{2+}$ in $\mathrm{HCl} 0.1 \mathrm{~mol} \mathrm{~L}^{-1}$ with deposition potential of $-0.05 \mathrm{~V}$, accumulation time $180 \mathrm{~s}$, amplitude $50 \mathrm{mV}$ and frequency of $25 \mathrm{~Hz}$. (A) PAni-ES/AuNPs LB films, (B) OMt/AuNPs LB films and (C) OMt/AuNPs/PAni-ES nanocomposite LB films. All the films had 30 layers and were deposited onto ITO plates. The black line of voltammograms corresponds to LB films only in the presence of supporting electrolyte $\mathrm{HCl} 0.1 \mathrm{~mol} \mathrm{~L}^{-1}$.
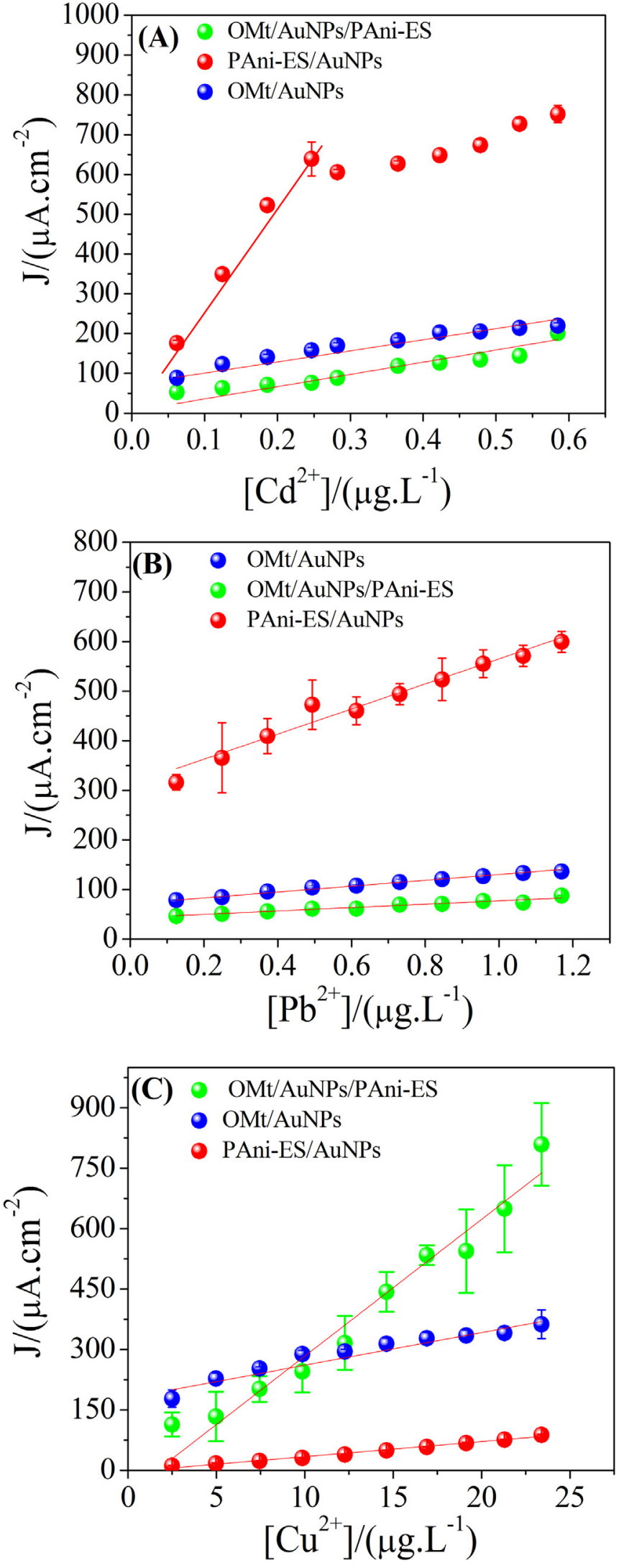

Fig. 10. Analytical curves for detection of metallic ions with electrodes modified with PAni-ES/AuNPs, OMt/AuNPs and OMt/AuNPs/PAni-ES. (A) $\mathrm{Cd}^{2+}$, (B) $\mathrm{Pb}^{2+}$ and (C) $\mathrm{Cu}^{2+}$. 


\section{Appendix A. Supplementary data}

Supplementary data associated with this article can be found, in the online version, at http://dx.doi.org/10.1016/j.snb.2016.06.022.

\section{References}

[1] C.-W. Chiu, T.-K. Huang, Y.-C. Wang, B.G. Alamani, J.-J. Lin, Intercalation strategies in clay/polymer hybrids, Prog. Polym. Sci. 39 (2014) 443-485.

[2] A. de Barros, M. Ferreira, C.J.L. Constantino, M. Ferreira, Nanocomposites based on LbL films of polyaniline and sodium montmorillonite clay, Synth. Met. 197 (2014) 119-125.

[3] R.A. Schoonheydt, Functional hybrid clay mineral films, Appl. Clay Sci. 96 (2014) 9-21.

[4] S.A. Hussain, S. Chakraborty, D. Bhattacharjee, R.A. Schoonheydt Incorporation of nano-clay saponite layers in the organo-clay hybrid films using anionic amphiphile stearic acid by Langmuir-Blodgett technique, Thin Solid Films 536 (2013) 261-268.

[5] C.-W. Chiu, J.-J. Lin, Self-assembly behavior of polymer-assisted clays, Prog. Polym. Sci. 37 (2012) 406-444.

[6] C. Medina-Plaza, C. Garcia-Cabezon, C. Garcia-Hernandez, C. Bramorski, Y. Blanco-Val, F. Martin-Pedrosa, T. Kawai, J.A. de Saja, M.L. Rodriguez-Mendez, Analysis of organic acids and phenols of interest in the wine industry using Langmuir-Blodgett films based on functionalized nanoparticles, Anal. Chim. Acta 853 (2015) 572-578

[7] S. Gupta, N. Singh, M. Sastry, R. Kakkar, R. Pasricha, Controlling the assembly of hydrophobized gold nanoparticles at the air-water interface by varying the interfacial tension, Thin Solid Films 519 (2010) 1072-1077.

[8] Q. Xi, X. Chen, D.G. Evans, W. Yang, Gold nanoparticle-embedded porous graphene thin films fabricated via layer-by-layer self-assembly and subsequent thermal annealing for electrochemical sensing, Langmuir 28 (2012) 9885-9892.

[9] C. Medina-Plaza, L.N. Furini, C.J.L. Constantino, J.A. de Saja, M.L. Rodri--guez-Mendez, Synergistic electrocatalytic effect of nanostructured mixed films formed by functionalised gold nanoparticles and bisphthalocyanines, Anal. Chim. Acta 851 (2014) 95-102.

[10] W. Guo, Y. Pi, H. Song, W. Tang, J. Sun, Layer-by-layer assembled gold nanoparticles modified anode and its application in microbial fuel cells, Colloids Surf. Physicochem. Eng. Asp. 415 (2012) 105-111.

[11] R. Sardar, A.M. Funston, P. Mulvaney, R.W. Murray, Gold nanoparticles: past, present, and future, Langmuir 25 (2009) 13840-13851.

[12] V.V. Mody, R. Siwale, A. Singh, H.R. Mody, Introduction to metallic nanoparticles, J. Pharm. Bioallied Sci. 2 (2010) 282-289.

[13] D.-M. Hou, X.-L. Chi, X.-L. Wang, F. Yin, Preparation of two-dimensional nano-Au particles monolayer and its application in bioelectrochemistry, Chin. J Anal. Chem. 37 (2009) 1313-1318.

[14] C.O. Baker, B. Shedd, R.J. Tseng, A.A. Martinez-Morales, C.S. Ozkan, M. Ozkan, Y. Yang, R.B. Kaner, Size control of gold nanoparticles grown on polyaniline nanofibers for bistable memory devices, ACS Nano 5 (2011) 3469-3474.

[15] A. Safavi, E. Farjami, Construction of a carbon nanocomposite electrode based on amino acids functionalized gold nanoparticles for trace electrochemical detection of mercury, Anal. Chim. Acta 688 (2011) 43-48.

[16] D. Yu, Y. Zeng, Y. Qi, T. Zhou, G. Shi, A novel electrochemical sensor for determination of dopamine based on AuNPs@SiO2 core-shell imprinted composite, Biosens. Bioelectron. 38 (2012) 270-277.

[17] X. Zou, H. Bao, H. Guo, L. Zhang, L. Qi, J. Jiang, L. Niu, S. Dong, Mercaptoethane sulfonate protected, water-soluble gold and silver nanoparticles: syntheses, characterization and their building multilayer films with polyaniline via ion-dipole interactions, J. Colloid Interface Sci. 295 (2006) 401-408.

[18] J.-W. Park, J.S. Shumaker-Parry, Structural study of citrate layers on gold nanoparticles: role of intermolecular interactions in stabilizing nanoparticles, J. Am. Chem. Soc. 136 (2014) 1907-1921.

[19] C. Lavenn, F. Albrieux, A. Tuel, A. Demessence, Synthesis, characterization and optical properties of an amino-functionalized gold thiolate cluster: Au10(SPh-pNH2)10, J. Colloid Interface Sci. 418 (2014) 234-239.

[20] G. Tanami, V. Gutkin, D. Mandler, Thin nanocomposite films of polyaniline/Au nanoparticles by the Langmuir-Blodgett technique, Langmuir 26 (2010) 4239-4245.

[21] L. Zou, Y. Li, S. Cao, B. Ye, Gold nanoparticles/polyaniline Langmuir-Blodgett film modified glassy carbon electrode as voltammetric sensor for detection of epinephrine and uric acid, Talanta 117 (2013) 333-337.

[22] C. García-Hernández, C. García-Cabezón, C. Medina-Plaza, F. Martín-Pedrosa, Y. Blanco, J.A. de Saja, M.L. Rodríguez-Méndez, Electrochemical behavior of polypyrrol/AuNP composites deposited by different electrochemical methods: sensing properties towards catechol, Beilstein J. Nanotechnol. 6 (2015) 2052-2061.

[23] A. de Barros, M. Ferreira, C.J. Leopoldo Constantino, J.R. Ribeiro Bortoleto, M. Ferreira, Synergy between polyaniline and OMt clay mineral in Langmuir-Blodgett films for the simultaneous detection of traces of metal ions, Acs Appl. Mater. Interfaces 7 (2015) 6828-6834.

[24] C. Medina-Plaza, C. Garcia-Cabezon, C. Garcia-Hernandez, C. Bramorski, Y. Blanco-Val, F. Martin-Pedrosa, T. Kawai, J.A. de Saja, M.L. Rodriguez-Mendez, Analysis of organic acids and phenols of interest in the wine industry using
Langmuir-Blodgett films based on functionalized nanoparticles, Anal. Chim. Acta 853 (2015) 572-578.

[25] I. Gofberg, D. Mandler, Preparation and comparison between different thiol-protected Au nanoparticles, J. Nanopart. Res. 12 (2009) 1807-1811.

[26] T. Berzina, A. Pucci, G. Ruggeri, V. Erokhin, M.P. Fontana, Gold nanoparticles-polyaniline composite material: synthesis, structure and electrical properties, Synth. Met. 161 (2011) 1408-1413.

[27] N.A. Kotov, F.C. Meldrum, J.H. Fendler, E. Tombacz, I. Dekany, Spreading of clay organocomplexes on aqueous solutions: construction of Langmuir-Blodgett clay organocomplex multilayer films, Langmuir 10 (1994) 3797-3804.

[28] A. Riul Jr., L.H.C. Mattoso, G.D. Telles, P.S.P. Herrmann, L.A. Colnage, N.A. Parizotto, V. Baranauskas, R.M. Faria, O.N. Oliveira Jr., Characterization of Langmuir-Blodgett films of parent polyaniline, Thin Solid Films 284 (1996) 177-180.

[29] M.K. Ram, M. Salerno, M. Adami, P. Faraci, C. Nicolini, Physical properties of polyaniline films: assembled by the layer-by-layer technique, Langmuir 15 (1999) 1252-1259.

[30] S.W. Karickhoff, G.W. Bailey, Optical absorption spectra of clay minerals, Clays Clay Min. 21 (1973) 59-70.

[31] D.R. Paul, L.M. Robeson, Polymer nanotechnology: nanocomposites, Polymer 49 (2008) 3187-3204

[32] B.N. Narayanan, R. Koodathil, T. Gangadharan, Z. Yaakob, F.K. Saidu, S. Chandralayam, Preparation and characterization of exfoliated polyaniline/montmorillonite nanocomposites, Mater. Sci. Eng. B 168 (2010) 242-244.

[33] A.F. Baldissera, J.F. Souza, C.A. Ferreira, Synthesis of polyaniline/clay conducting nanocomposites, Synth. Met. 183 (2013) 69-72.

[34] P. Thomas, K. Dwarakanath, K.B.R. Varma, In situ synthesis and characterization of polyaniline-CaCu3Ti4012 nanocrystal composites, Synth. Met. 159 (2009) 2128-2134.

[35] M. Ferreira, K. Wohnrath, R.M. Torresi, Constantino, R.F. Aroca, Oliveira, J.A. Giacometti, Spectroscopic and electrochemical characterization of polyaniline and a ruthenium complex, mer-[RuCl3(dppb)(py)], in the form of Langmuir-Blodgett films, Langmuir 18 (2002) 540-546.

[36] G.M. do Nascimento, V.R.L. Constantino, R. Landers, M.L.A. Temperini, Aniline polymerization into montmorillonite clay: a spectroscopic investigation of the intercalated conducting polymer, Macromolecules 37 (2004) 9373-9385.

[37] C. Chen, X. Niu, Y. Chai, H. Zhao, M. Lan, Bismuth-based porous screen-printed carbon electrode with enhanced sensitivity for trace heavy metal detection by stripping voltammetry, Sens. Actuators B Chem. 178 (2013) 339-342.

[38] G.M.S. Alves, J.M.C.S. Magalhães, P. Salaün, C.M.G. van den Berg, H.M.V.M. Soares, Simultaneous electrochemical determination of arsenic copper, lead and mercury in unpolluted fresh waters using a vibrating gold microwire electrode, Anal. Chim. Acta 703 (2011) 1-7.

[39] H. Lin, M. Li, D. Mihailovič, Simultaneous determination of copper, lead, and cadmium ions at a Mo6S9-xIx nanowires modified glassy carbon electrode using differential pulse anodic stripping voltammetry, Electrochim. Acta 154 (2015) 184-189.

[40] D. Li, J. Jia, J. Wang, Simultaneous determination of Cd(II) and $\mathrm{Pb}$ (II) by differential pulse anodic stripping voltammetry based on graphite nanofibers-nafion composite modified bismuth film electrode, Talanta 83 (2010) 332-336

[41] O. El Tall, N. Jaffrezic-Renault, M. Sigaud, O. Vittori, Anodic stripping voltammetry of heavy metals at nanocrystalline boron-doped diamond electrode, Electroanalysis 19 (2007) 1152-1159.

[42] M.B. Gumpu, S. Sethuraman, U.M. Krishnan, J.B.B. Rayappan, A review on detection of heavy metal ions in water-an electrochemical approach, Sens. Actuators B Chem. 213 (2015) 515-533.

[43] Y. Dong, Y. Ding, Y. Zhou, J. Chen, C. Wang, Differential pulse anodic stripping voltammetric determination of $\mathrm{Pb}$ ion at a montmorillonites/polyaniline nanocomposite modified glassy carbon electrode, J. Electroanal. Chem. 717 (2014) 206-212.

[44] L. Zhu, L. Xu, B. Huang, N. Jia, L. Tan, S. Yao, Simultaneous determination of $\mathrm{Cd}(\mathrm{II})$ and $\mathrm{Pb}$ (II) using square wave anodic stripping voltammetry at a gold nanoparticle-graphene-cysteine composite modified bismuth film electrode, Electrochim. Acta 115 (2014) 471-477

[45] P. Silva, M. El Khakani, M. Chaker, A. Dufresne, F. Courchesne, Simultaneous determination of $\mathrm{Cd} \mathrm{Pb}$, and $\mathrm{Cu}$ metal trace concentrations in water certified samples and soil extracts by means of $\mathrm{Hg}$-electroplated-Ir microelectrode array based sensors, Sens. Actuators B Chem. 76 (2001) 250-257.

\section{Biographies}

Anerise de Barros Bachelor in Chemistry in 2008, Master degree and Ph.D. in Materials Science at 2011 from the Federal University of São Carlos and at 2015 from the State University Paulista, respectivelly. Her scientific work is mainly interest in preparation and characterization of surface modificated by nanostructure thin films for sensing application, addionally she has experience in synthesis of conducting polymer and metallic nanoparticles. Nowadays, she is a Post-doctorate in Functional Materials Laboratory, Chemistry Institute in State University of Campinas acting in surface modification with metallic nanoparticles for surface-enhanced Raman scattering (SERS) active platforms. 
Carlos José Leopoldo Constantino Bachelor in Physics (USP - 1993) and Production and Materials Engineering (UFSCar - 1997). He took his Master in Applied Physics (USP - 1995) and PhD in Materials Science and Engineering (USP - 1999). He was Post-Doc fellow at Windsor University (Canada - 2001), EMBRAPA (Sao Carlos 2002) and Universidad de Valladolid (Spain - 2009). Nowadays he is Associated Professor at Universidade Estadual Paulista (UNESP). His research fields involve spectroscopic characterization of materials by micro-Raman and surface-enhanced Raman scattering (SERS), nanostructured thin films of organic materials for sensing and optical devices, polymeric films for engineering applications.

José Roberto RibeiroBortoleto Physics degree from the São Paulo State Univerty in 1997. Master degree and $\mathrm{Ph}$. D in physics from the State University of Campinas in 2000 and 2005, respectively. Post-doctorate from Pennsylvania State University at 2009. He is currently Assistant Professor at the São Paulo State University. He has experience in the area of Physics, with emphasis on Condensed Matter Physics, acting on the following topics: Atomic force microscopy, chemical beam epitaxy and magnetron sputtering, InP/InGaP quantum dots, III-V semiconductors and $\mathrm{ZnO}$ based materials.
Nilson Cristino da Cruz Received his PhD degree in Science from the Universidade Estadual de Campinas in 1999. Since 2003 he is teaching at Univ Est Paulista. His scientific work is mainly devoted to surface modifications by PECVD, Plasma Immersion Ion Implantation and Deposition and Plasma Electrolytic Oxidation.

Marystela Ferreira Obtained her bachelor degree in Chemistry in 1993, Master degree and Ph.D. in Physical Chemistry in 1996 and 2000, respectively, at Universidade de São Paulo, São Carlos - SP(Brazil). Her main fields of interest are preparation and characterization of nanostructured thin films for sensing, and Layer-by-Layer and Langmuir-Blodgett films of several materials for sensing different analytes in environmental and biological samples. She is teaching and researching at Universidade Federal de São Carlos, Sorocaba - SP since 2007. 